\section{DNA in the mind's eye}

Richard L. Gregory

The Astonishing Hypothesis: The Scientific Search for the Soul. By Francis Crick. Scribner's: 1994. Pp. 317. \$25. To be published in the United Kingdom by Simon and Schuster on 19 May at $£ 16.99$.

FROM the extraordinary triumph 40 years ago of unravelling the structure of DNA, Francis Crick turned to questions of how the brain works. It is surely no coincidence that over the past few years the institute to which he moved, the Salk Institute in La Jolla, has with the University of California at San Diego become an important magnet for brain research, attracting established and up-and-coming scientists of all kinds - and brain research requires all kinds - as well as philosophers prepared to learn anatomy and physiology and to consider the results of experiments, including psychological phenomena.

Here Crick sits at the centre of a vibrant web. When he tweaks a thread, people will travel any distance to hear and be heard by him, sometimes only to be told to think again. These Sun-worshippers are prepared to ask difficult questions and to seek answers wherever they may be found, whether in the details of molecular chemistry or in the structure and function of the cunning cortex.

A shared vision of these travellers is that of understanding vision. The way in which we see was contemplated by the Greeks, but only since the middle of the nineteenth century has the scientific method been applied consistently to the problem, and there is still a lack of agreement on how best to discover the processes underlying vision and consciousness. This book is an account of this dramatic enterprise by one of the greatest living biologists, written with clarity and charm.

There is, to be perhaps too frank, a general feeling that Nobel laureates who change tack in mid-life are loose cannons. But Crick has chosen his targets with considerable care, and has succeeded in piercing many revealing holes through barriers of puzzlement and ignorance. $\mathrm{He}$ sets his sights firmly on neurons, believing that a great deal of what other people consider to be important about the brain and consciousness is irrelevant, misleading or a waste of time. Quantum mechanics, for example, is judged to be neither here nor there: although quantum principles are necessary for an understanding of how snooker balls maintain their shape and bounce about, the basic principles of matter can and should be ignored. For Crick, the actors in the play of the brain are the billions of interconnected neurons and their electrochemical signals. (Perhaps the actors are rulebased symbols, although Crick doesn't models of cognition, no doubt wisely

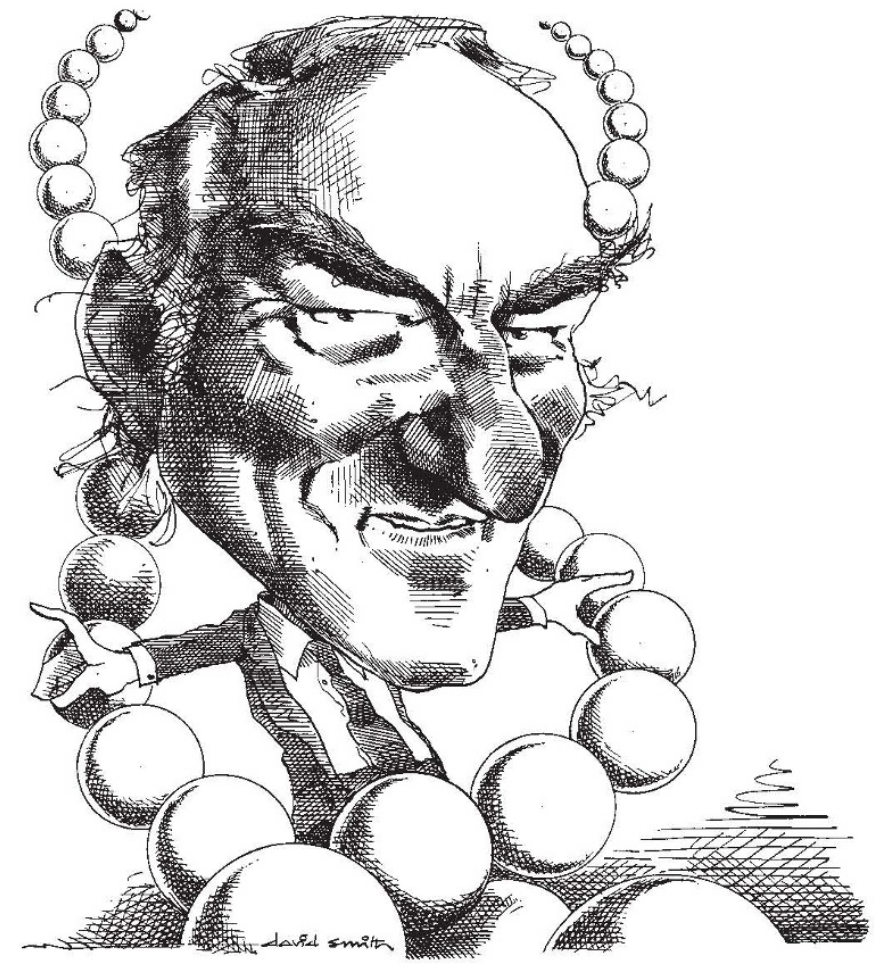

for his own purposes.)

The "Astonishing Hypothesis" is that there is no homunculus, or little person, inside our heads, constituting the self; that there is no extra-vehicular soul, only the immensely complex and currently little understood interactive activity of neurons. Thus, as Julian Offray de la Mettrie said in 1748 (and he was thrown out of his medical practice in Paris for saying it), man is a machine. As we come to see this, the limitations of what is meant by 'machine' become relaxed, but not so far that anything goes, or rather that anything is accepted. What is lost is Descartes' notion of an immaterial mind that lies beyond scientific explanation. Yet even this position has its semantic problems, for what might the term 'scientific' accommodate in a hundred years from now? This uncertainty is why Crick calls move far in the direction of symbolic his view a hypothesis: he concedes that his neuronal account remains unproved and admits that he lacks a theory of consciousness - of why red is red.

We are guided through the delightful intricacies of the psychology of vision (especially the filling-in of blind regions and phenomena of ambiguity where perception takes off from stimuli); attention and memory; the structure of the brain; and the workings of its neurons. There is a useful chapter on the power and weakness of experimental techniques, including microelectrode recording, patchclamping and the latest imaging methods. Effects of brain damage are also discussed. All this leads to potentially important speculations, the upshot being that consciousness remains mysterious. But Crick will continue to contemplate the future of brain science - the detailed and comprehensive study of neurons.

What he seeks are neural correlates of sensations, thoughts and perceptions: that is, brain activity likely to be related to 'qualia', the subjective quality of mental experience. If these assocations are found, a philosopher might still say: "So what?" Crick has no time for philosophers, at least those without knowledge of neuroanatomy and function (so he values Patricia and Paul Churchland's contributions), but even he would probably have to admit that the age-old question of the nature of consciousness remains, for correlations can never directly and unambiguously provide answers or prove cause and effect. Day is followed by night, but it is nonsense to say that one is caused by the other - a proper understanding of the phenomenon involves a leap beyond everyday experience to a mental picture of the Earth spinning around the Sun. By analogy, some philosophers would say that Crick is too 'Earth-bound' to explain how qualia are related to (caused by?) neuronal activity.

Crick dedicates his book to Christof Koch, who has worked with him in developing many of the ideas it contains. They both agree with the psychologist V.

\section{S. Ramachandran that}

visual perception does not involve intelligent deduction of the type we use in constructing an argument, nor does it involve the vague idea that the brain simply 'resonates' to the visual input. Neither does it require the solving of elaborate equations, as often implied by AI [artificial intelligence] researchers. Instead [Ramachandran] believes perception "uses rules of thumb, short-cuts, and clever sleight-ofhand tricks that are acquired by trial and 
error through millions of years of natural selection. This is a familiar strategy of biology" [p. 77].

The digital computer is rejected as a model of the brain in favour of a scheme involving many special processors probably consisting of interacting nets of neurons. Cortical organization is seen as being dictated by the need for short pathways and the efficient use of a limited (though enormous) number of neurons. This wiring requirement produces specialized, highly interactive modules linked to nearby functionally related ones, like 'villages' within a city.

Crick argues that far more detailed knowledge of human brain anatomy particularly the cortical layers - is required to make any real progress in locating the main sites of possible "awareness neurons". His favourite candidates are the inner cortical layers and subcortical structures, especially the 'gateway to the cortex', the thalamus. And because many specialized visual processors deal separately with form, movement, depth, colour and so on, there is the 'binding problem' of how their contributions come together to give coherent, vivid perceptions. Crick thinks that neural mechanisms of attention may hold the key, with neural oscillations as the basis of selective attention and captured synchronous outputs of processors underlying binding.

But what of qualia? Why is red red? Crick would seem to agree with Stuart Sutherland's statement: "Consciousness is a fascinating but elusive phenomenon; it is impossible to specify what it does, or why it evolved. Nothing worth reading has been written on it." But by seeking neural correlates, he hopes to capture consciousness from philosophy. And by rejecting special properties (as in vitalism), he emphasizes emergence, pointing out that novelty generated by combinations of particles, or properties, even at the molecular level, is the essence of chemistry and life. Here 'emergence' does not mean mysteries popping out of the undergrowth; it means that with a sufficient understanding of interactive processes, we should come to understand why a complex whole has properties its parts lack on their own, and how the parts are modified by the context in which they lie.

This is a flexible kind of atomism. Perhaps the ultimate aim is to derive a conceptual model for understanding the emergence of consciousness from the physics of neurons. All this from DNA, through the evolution of intelligence. Dare we call it Darwinian Neural Awareness?

Richard L. Gregory is in the Department of Psychology, University of Bristol, Bristol BS8 21H, UK.

\section{The talking ape}

Christopher Longuet-Higgins

The Language Instinct: How the Mind Creates Language. By Steven Pinker. Morrow: 1994. Pp. 494. \$23. To be published in the United Kingdom by Viking on 11 April at $£ 20$.

HERE at last is a marvellously readable book about language, written by a real expert. Steven Pinker tackles with wit and erudition the kinds of question everyone asks about language. Why do immigrants have such trouble learning a new tongue, only to have their children ridicule their grammatical mistakes? Why is the Maple Leafs hockey team not called the Maple Leaves? Have scientists actually succeeded in reconstructing the first language

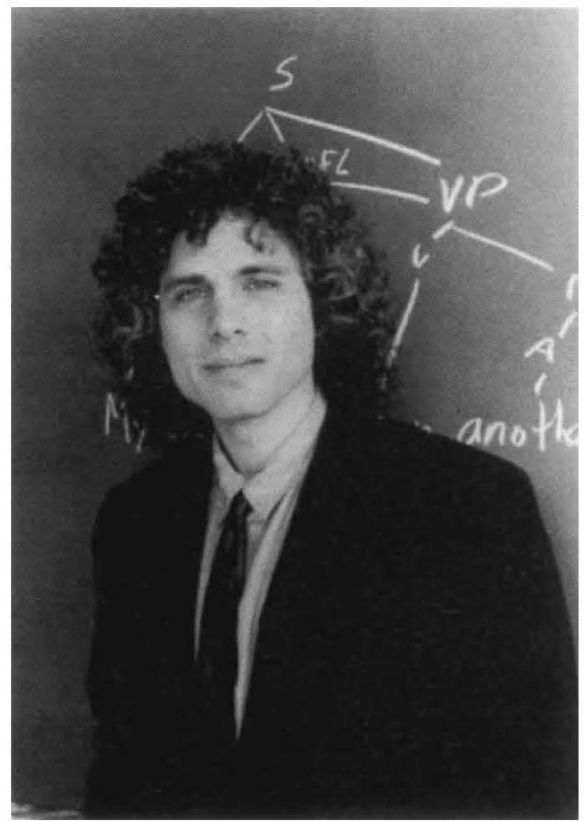

Pinker - no linguistic hang-ups.

spoken on Earth? Are there genes for grammar? Can chimpanzees really learn human sign languages? How could language have evolved? Does a person's language control the way he or she thinks? Is the English language gradually falling apart?

To these questions Pinker brings not only an expertise in linguistics and psychology and a wide knowledge of biology, but also an ability to understand the ordinary person's linguistic hang-ups and to shake them loose with gentle ridicule. Here (slightly condensed) is the opening of his chapter on "The Language Mavens" (the word 'maven' was coined by the critic William Safire for a self-appointed regulator of the English language):

Imagine you are watching a nature documentary. The video shows the usual gorgeous footage of animals in their natural habitats. But the voiceover reports some disturbing facts. White-crowned sparrows carelessly debase their calls, and the song of the humpback whale contains several wellknown errors. Your reaction would probably be, What on earth could it mean for the song of the humpback whale to contain an 'error'? Who is this announcer, anyway?

All the best writers in English, at all periods, including Shakespeare and most of the mavens themselves, have been among the most flagrant flouters [of the mavens' rules]. The rules conform neither to logic or to tradition, and if they were ever followed they would force writers into fuzzy, clumsy, wordy, ambiguous, incomprehensible prose, in which certain thoughts are not expressible at all.

The principal theme of The Language Instinct is implicit in its title. Human language defies explanation as the automatic response of a general-purpose brain to the complex stimuli of early childhood; it must, as Noam Chomsky has always insisted, be a largely inherited faculty. But while Chomsky is fiercely agnostic about the evolutionary origin of language, Pinker makes a convincing case that language evolved by a fully Darwinian mechanism, like the elephant's trunk. (Those who have lost their childhood wonder at this astonishing proboscis will regain it as soon as they read the breathtaking first paragraph on page 332 .)

There are other points at which Pinker departs from Chomskian orthodoxy, most notably in postulating a mental language - "mentalese" - in which we marshal our thoughts before expressing them in, say, English, and into which we translate what other people say to us. The value of such a hypothesis depends, of course, on its predictive power, and one may prefer an account of thinking more along the lines laid down in Philip Johnson-Laird's influential book Mental Models (Harvard University Press/Cambridge University Press, 1983). But at least the concept of an internal language of the mind seems preferable to the simplistic idea that Englishmen think in English while Frenchmen think in French - a hypothesis that creates acute problems about how chess players or tennis players or flute players might think, and how people manage to translate, however awkwardly, from one language into another.

Whatever its eventual impact on linguistics and psychology, The Language Instinct will undoubtedly be greeted as a distinguished contribution to the lay understanding of science. In the past, linguists have been less effective as communicators than, say, astronomers or biologists, but now the educated layman will have no excuse for imagining that 'deep structure' is essentially the same thing as 'universal grammar'. (There is an excellent glossary in which such misconceptions can be quietly sorted out.) And Pinker is determined to give us some hard, detailed information to get our minds 